With this idea in view, the entire library has been classified according to the Dewey decimal system, which is used by most public and educational libraries. No classification method is perfect; but any system has advantages over no system, and the Dewey plan has the advantages of wide usage and exceptionally thorough subdivision in nearly all classes. The chief disadvantage is that some of the sections in chemistry and technology are urgently in need of revision.

Minor details, such as arrangement on the shelves, pamphlet filing, etc., are made to follow as nearly as possible the best current 11sage. Custom, however, is made subordinate to convenience. The system is shaped to fit the library, not the library to fit the systen.

The plan of administration, or method of making the library useful, is of course intended to render the maximum of service. With the exception of the standard reference works, nearly all the literature is freely loaned to accredited users of the library, with the understanding that it shall be returned in seven days. Renewal of loans is permitted, and is quite commonly requested. A custodian has charge of the loaning and returning. She is generally kept quite busy between times typing the various documents prepared by the librarian, and keeping up the routine work of the library.

The library room is large enough to provide ample study space, in addition to the stacks. Most of the men who read there are familiar enough with the shelf arrangement to find the volumes they need; but the custodian is always ready to give such information on request.

Although on casual inspection ours looks like a decidedly chemical library, there is much other material. All of Dewey's ten main divisions of human thought and study are represented, except philosophy and religion. Rough grouping of the literature on the shelves reveals the following dry but instructive figures:

Chemistry, of the variety often misnamed pure, makes up about 40 per cent of the texts and reference works, 20 to 25 per cent of the pamphlets and unbound periodicals, and nearly 75 per cent of the bound periodicals. Technical chemistry occupies some 30 per cent of the text and reference shelves, 25 per cent of the pamphlet and unbound periodical files, and 25 per cent of the space devoted to bound periodicals. This branch maintains the least erratic ratio of any:

Physics comprises about 5 per cent of the texts and reference works and of the unbound periodicals, hardly more than I per cent of the pamphlets, and a small but slowly increasing proportion of the bound periodicals.

Engineering forms some 5 per cent of the texts and reference works, IO per cent of the pamphlets, and 15 per cent of the unbound periodicals, but considerably less than 5 per cent of the bound periodicals.

A wide variety makes up the remainder. Library science, business, finance, legislation, insurance, labor problems-all the subjects that interest a large manufacturing establishment must needs be more or less thoroughly represented.

In order to keep abreast of the times, 67 periodicals are currently received, and we have a waiting list of about 20 more to be added to our subscription list as soon as we can begin to get them from Germany and Austria. Partial files of about 30 others, not currently received, are on the library shelves.

There is plenty of variety in the types of service expected of a research library, but they naturally group themselves into only two classes: first comes the duty of providing references, and second that of facilitating their use.

The members of a live research organization would like to have at hand all the literature needful for the solving of any problem. Failing of this ideal, which is not likely to be attained this side of the millennium, the next best method is to know the habitat of all existing literature needed but not possessed.
Once discovered, references can usually be purchased or borrowed; if neither of these is possible, a copy or abstract can nearly always be obtained. The cameragrams furnished by the John Crerar Library of Chicago constitute one of the best sources of copies; but there are many others.

Providing the literature is only the beginning of the twofold service to be rendered, bibliographies, abstracts, translations, indexes, and other aids are constantly needed to increase the usefulness of the library's treasure-house. An alert watch must be kept for new developments.

Patents form a problem by themselves. The conditions under which patents and their records may be useful vary so much with different companies, that each must needs work out its own plans for handling the problem. The most crying need is adequate indexing of U.S. patents, a task which our Government has not yet taken very seriously to heart.

Improvements are needed in both divisions of research library service. In the providing of literature, resumption of mail service from Central Europe will open up sources of some of the valuable reference work published there. But a much better prospect is the production, in English, of more thorough and reliable chemical literature than the Germans ever wrote. We hope great things from the tentative plans for compiling English reference works in the various fields of chemistry; and we anticipate that research libraries will be called on to contribute their share toward the compilation thereof.

In the second class, the facilitation of reference work, the prominent need is indexing. If all the technical literature of the world could be card-indexed and if the cards could be distributed by subscription, like Library of Congress cards, the research librarian's life would be a garden of roses. Since that cannot be, each library must do large quantities of indexing for itself, or lose the benefits to be gained thereby.

All the above observations have been made with the dyestuffs industry in mind but in the main they are equally true for any research organization. A research library is a highly specialized reference library; but it dares not be narrowly specialized. It must reach into nearly as broad a field as its greater cousin, the public reference library. The latter must serve many industries more or less superficially; the former must serve one industry thoroughly in its main interest and must make some provision for its occasional interests.

\section{INTERNAL PUBLICITY AS AN AID TO THE LABORATORY}

By S. M. MAsse , Publicity Department, National Carbon Co., Inc., Cleveland, Ohio

The nature of publicity work, as generally understood, is to circulate information. Advertising is one form of publicity; newspapers are another source. In both these instances the information is sent from the place of business to the outside world. This might be termed external publicity. Now, how about reversing the process, that is, bringing the information from without the plant to the organization within? This is internal publicity. It has been said that in order to stabilize business there should be just as much intake of publicity as there is output.

My mission to-day is to tell about the use of internal publicity as an aid to the laboratory.

The busy chemist has not the time and opportunity to keep in touch with all the latest technical and trade paper information. Oftentimes the most timely subject may be found in some seemingly obscure magazine, or some foreign topic may have a valuable application to the process at hand and be contained in an article which would probably be the last place the chemist would be apt to look.

This brings me to the issue of most vital interest in this discussion. It is the Weekly Index service of the National Carbon Co., Inc., and concerns the relationship of the industrial library 
to the laboratory. Of course we have other departments to serve at the same time so that the Weekly Index is not limited to the laboratory alone but serves all departments of the company.

Instead of placing this work in direct charge of the library staff we employ the services of technical men. These men are either chemists or electrical engineers. Together with the advertising personnel and library staff they comprise what is known as the Publicity Department.

We subscribe to approximately go publications, technical, trade, and business papers. Of the more important publications we get a number of magazines to take care of the demand. The work of the publicity men is to go through these various publications each week and choose therefrom the articles of interest to the various departments. A comment is then made on each article so as to bring out its special application to the organization. These articles are then listed under their respective publications on what we call our Weekly Periodical Index and Reviere. The Index also includes all new books received, pamphlets, patents, etc. Printed copies of the Index are then distributed among all interested employees, including all of our several plants scattered throughout the country. Space is provided at the left of the Index page for the recipient of the sheet to fill in his name and department. Then, by checking the desired articles and sending the sheet back to the library, the person receives the magazines, books, patents, or whatever he has checked.

It is often true that the articles checked are not necessarily in chemical publications but still contain information which the chemist can appreciate. The Index includes foreign articles which are translated on request. Although it might be pointed out that Chemical Abstracts would cover much of the technical information, our local index presents the desired reference in a nutshell and we feel that we can give as a comment an application with a more direct bearing than what would be construed from reading the comments given in Chemical Abstracts. Moreover, articles of a purely business point of view are included and often used to good advantage by the laboratory staff.

We also keep a regular mailing list comprising names of all those who are interested in certain publications and wish to secure them regardless of their appearance on the Weekly Index. This list is carefully selected and includes only those persons who, through their type of work, would be expected to keep in touch with the particular magazine in question. Other persons would have to take their turn farther down in the list.

After the Weekly Index has been entirely circulated, all articles are filed according to the Dewey decimal system on large manila cards. Thus, if at any time one wishes to review any articles under a particular heading, he can receive this information from the library files. Another phase of our information stock may be gathered from the catalogue files in which are found all descriptive literature of products related to our own.

Sometimes someone desires special information on a particular subject. In this event he simply calls on the phone or writes the Publicity Department and the information is gathered by the technical force. Quite often this requires immediate service, as, for instance, when a laboratory man needs certain information which he would otherwise have to secure for himself by leaving his work. If desired, a bibliography on any subject will be formulated although by now we are equipped with practically all bibliographies of interest to the company. In spite of the fact that we have over 4000 volumes in our library the technical force sometimes has to seek information from outside sources or correspond with related industrial concerns. In respect to this latter, we have been agreeably surprised at the responsive spirit to coöperate which emanates from outside concerns.

Bulletins, abstracts, tables, etc., are formulated from time to time, one example being a small booklet called "Technical
Periodicals." In it are listed about 500 technical periodicals giving the library where each one may be found, and also from what date these periodicals have been kept. The libraries include about ten of the various public, college, and commercial libraries scattered throughout the city of Cleveland. There is also our company publication-the Carbon News-which is entitled to much consideration as establishing an esprit de corps among our workers and no doubt this family style of house-organ is being used in the majority of industrial concerns to-day.

One thing more must be mentioned as included in our publicity service. It is the photographic studio which functions as a means of visualizing so much better than written words will sometimes do. When someone desires a permanent copy of material which the library reserves for reference purposes only, we can supply photostatic copies from our studio. This is especially advantageous for taking care of the needs of our distant factories.

I want to say in closing that the Publicity Department of the National Carbon Co., Inc., is at all times glad to help any industrial establishment or interested persons on questions of which we have a specialized knowledge. Our business is carbon manufacture, yet this entails a number of related subjects which should cover points of interest to many of those present here.

\section{LIBRARY SERVICE OF THE NEW JERSEY ZINC COMPANY}

By LEONORE A. TAFEL, New Jersey Zinc Company, New York City

The library system of the New Jersey Zinc Company grew out of the need, which made itself felt at different points throughout the Company, of having close at hand working collections of books. These collections were at first small and disconnected, but as the interests of the Company grew, the demand arose for books on a greater number of technical subjects, and a means of carrying on systematized research work. The need of library service proved to be threefold: (I) The need of standard reference works for constant use; (2) provisions for systematic research work, which includes the compilation of bibliographies, access to sources, and translating and abstracting of material; (3) contact with current technical literature.

In order to extend these advantages to all members of the Company, and at the same time to administer the work in the most efficient and economical manner, these scattered libraries were organized, in 1917 , into one Company library, centralized in New York, with branches throughout the Company. The library is organized directly under the Technical Department, which department has charge of all research work. The administrative work is centralized in the New York library, including the ordering, classifying, and cataloguing of material for all libraries. Two branches have been entirely reorganized according to modern library methods, and it is planned to reorganize others and establish new centers as the need makes itself felt. Union catalogues of all books, pamphlets, and magazines in the Company library are maintained at four different points, and this material may be borrowed by any member of the Company. This organization work has proved worth while in making the library resources most accessible.

In ordering books, duplication is avoided as far as practicable, except in the case of standard reference books which are of constant use and must be near at hand when needed. These are duplicated freely and kept up to date. Of the newer technical books which may not prove of lasting interest, one copy is bought, as a rule, routed among the men interested, and finally placed in the branch where it will prove most useful, to be sent out on request to anyone desiring to read it.

Having established these reference collections at different points in the Company, and having arranged a system by which the reference work was coördinated, it was soon found necessary to render further aid to the research worker in the compilation 